\section{Manual de farmacologia psiquiátrica de Kaplan e Sadock}

Benjamin J. Sadock, Virginia A. Sadock; tradução de Maria Cristina Monteiro. Porto Alegre: Artmed, 2002, $3^{\text {a }}$ ed., 376 páginas

Esse manual foi escrito pelo casal Sadock, ambos psiquiatras e professores da Faculdade de Medicina da Universidade de Nova York, com a finalidade de servir como um guia psicofarmacológico com alcance em todas as faixas etárias. Pretende esgotar, no aspecto farmacológico, todas as possibilidades terapêuticas da clínica psiquiátrica atual. O original dessa tradução foi publicado no ano de 2001. Os autores oferecem uma apresentação concisa, clara e operacional que facilita o uso do manual, fazendo recomendações sobre a melhor forma de consultá-lo. Está repleto de tabelas, inclusive algumas no início do livro que servem para localizar mais rapidamente assuntos determinados de interesse do leitor. Enfatizam cuidadosamente que o manual não substitui os "Tratados" ou "Compêndios de Psiquiatria", servindo apenas como uma referência rápida.

Cada capítulo foi organizado para fornecer dados sobre: (1) nome e estrutura molecular do fármaco; (2) farmacocinética e farmacodinâmica; (3) preparações e dosagem; (4) indicações clínicas; (5) uso em populações especiais - crianças, idosos, grávidas e lactentes, assim como pacientes renais e hepatopatas; (6) reações adversas; e (7) interações farmacológicas. Todo capítulo finaliza com uma referência relativa a uma obra em que o leitor pode encontrar dados mais abrangentes sobre o assunto. Alguns capítulos são particularmente interessantes, pois abordam substâncias que não são habitualmente familiares aos psiquiatras, como agonistas de receptores alfa $a_{2}$-adrenérgicos, inibidores dos canais de cálcio, hidrato de cloral, dantroleno, agonistas de receptores dopaminérgicos e opióides, orlistat, sibutramina, sildenafil e ioimbina. Também são interessantes os capítulos sobre associações medicamentosas, exames laboratoriais, intoxicações e ervas psicoativas.

Destaque deve ser dado à forma de classificação das substâncias psicoativas, empregada pelos autores de acordo com a atividade farmacológica e o mecanismo de ação, substituindo as categorias tradicionais de antidepressivos, antipsicóticos, antimaníacos, ansiolíticos e estabilizadores de humor, tendência já presente em publicações anteriores do Compêndio de Psiquiatria de Kaplan e Sadock. Criticam a nomenclatura derivada originalmente de Delay e Deniker por empregar termos por demais amplos e que não refletem com precisão o uso clínico das substâncias, uma vez que uma mesma droga pode apresentar vários efeitos terapêuticos diferentes. Entretanto, os autores têm dificuldade em sustentar essa nova classificação, pois recorrem inúmeras vezes à terminologia por eles mesmos criticada, assim como classificam algumas substâncias simplesmente por seu nome químico (buspirona, carbamazepina, mirtazapina, nefazodone, trazodone, venlafaxina etc.). Essa tentativa de categorizar diferentemente as substâncias psicoativas é interessante e demonstra o momento pelo qual passa a ciência da psicofarmacologia, procurando ajustar-se aos conhecimentos crescentes das neurociências; todavia, a despeito dos avanços registrados, ainda há uma grande distância para se atingir uma maneira satisfatória de classificar modernamente os psicofármacos.

O capítulo sobre "Princípios

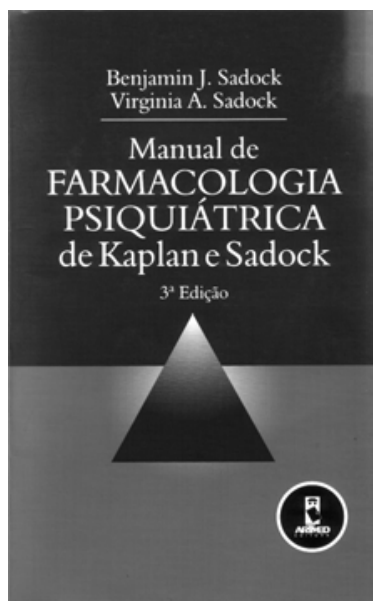
gerais de psicofarmacologia" é excelente, trazendo, entre outras informações, dados importantes sobre índices terapêuticos, classificação das drogas segundo seu potencial de abuso pelo Drug Enforcement Agency (DEA), alerta sobre as bulas dos medicamentos e explicações bastante didáticas sobre as interações medicamentosas. O livro está repleto de orientações terapêuticas úteis, como a equivalência entre as drogas antipsicóticas típicas, educação para o paciente que usa lítio, como fazer a aplicação IM dos antipsicóticos depot, entre outras, e curiosidades como a entrevista com amobarbital ("soro da verdade"), utilizada como diagnóstico auxiliar em algumas indicações clínicas.

Esse manual deixa claro a tendência atual da psiquiatria norte-americana pelo uso de medicações mais modernas, como observado na pág. 246: "o tratamento de manutenção da psicose a longo prazo com antagonistas de receptores dopaminérgicos tornou-se uma prática duvidosa", e, na pág. 281: "todas as indicações dos ADT também servem para os ISRS, que os têm substituído amplamente na prática clínica”. É necessário um olhar crítico para essas afirmações, que permita deslocá-las para a realidade do país, e também lembrar que não se dispõe, por exemplo, de medicação antidepressiva mais eficaz que os ADT e IMAO clássicos, destacando a importância de algumas dessas medicações "antigas" no manejo de casos refratários. Assim como as recomendações de dosagens utilizadas são específicas para população diferente da brasileira, podendo, portanto, requerer modificações na prática clínica nacional.

Nota-se que algumas questões poderiam ser melhor abordadas, como: uso de antidepressivos na depressão do transtorno bipolar I; uso de antipsicóticos depot; alterações da arquitetura do sono com os ISRS; síndrome de descontinuação das drogas serotonérgicas; e interações que envolvem o sistema do citocromo P450. Também, quando se refere à ação do medicamento como agonista ou antagonista de receptores, deveria constar se são receptores pré ou pós-sinápticos nos casos de localização nes- 
sas duas regiões ( $\left(\mathrm{alfa}_{2}, 5 \mathrm{HT}_{1 \mathrm{~A}}\right)$, já que costumam ter efeitos distintos. $\mathrm{E}$ as indicações clínicas da ziprasidona e da reboxetina nos pareceram excessivas. Encontram-se algumas incorreções no texto, que devem estar em processo de ajuste pelos editores, por exemplo: a citação do haloperidol como agonista de receptores de dopamina (pág. 64); zolpidem e zaleplon como agonistas não-benzodiazepínicos (pág. 86); "ocorre amnésia anterógrada de rebote com benzodiazepínicos" (pág. 89); e "risco de dependência psicológica no uso prolongado de benzodiazepínicos" (pág. 86). Em alguns momentos, os autores não citam o grau de evidências científicas que suportam as estratégias de tratamento indicadas, colocando da mesma forma abordagens bem estabelecidas cientificamente (potencialização do lítio aos antidepressivos) com abordagens experimentais (buspirona e clonazepam acelerando o efeito antidepressivo da fluoxetina).
As observações relatadas anteriormente não diminuem a importância desse livro, que consegue apresentar uma revisão atual, útil e ampla da atividade farmacológica em psiquiatria. À medida que pesquisas com rigor científico desvendam os "mistérios do cérebro", é permitido, cada vez mais, um aprimoramento clínico do psiquiatra, e é dentro desse escopo que esse manual deve ser situado. Essa obra traz uma visão das estratégias farmacológicas que o psiquiatra necessita conhecer em sua prática profissional, acrescentando informações em uma área do saber médico cada vez mais relevante.

Saint-Clair Bahls

Departamento de Psicologia da Universidade Federal do Paraná. 